\title{
Design on Rehabilitation of Landslide and Intake Waterproof Barrier of SHPP Nakra
}

\author{
Teodor Dimitrievski*, Dragan Dimitrievski, Atanas Strasheski Boris Bogoevski and Ljupco Dimitrievski \\ University of Ss Cyril and Methodius-Skopje, Macedonia
}

Submission: January 08, 2019; Published: January 29, 2019

*Corresponding author: Teodor Dimitrievski, Geing Krebs und Kiefer international, Skopje, Macedonia

\section{Abstract}

During the construction of small hydro power plant (SHPP) Nakra it was concluded that there is a need for developing of additional designs. The additional designs are related to the rehabilitation of landslide affecting the cut slopes near the future penstock and construction of waterproof barrier in front of the intake structure of the hydro power plant. This paper deals with some aspects related to the additional designs which are out of the original scope of the design works.

Keywords: Waterproof barrier; Landslide; Small hydropower plant; Piles; Grouting

Introduction

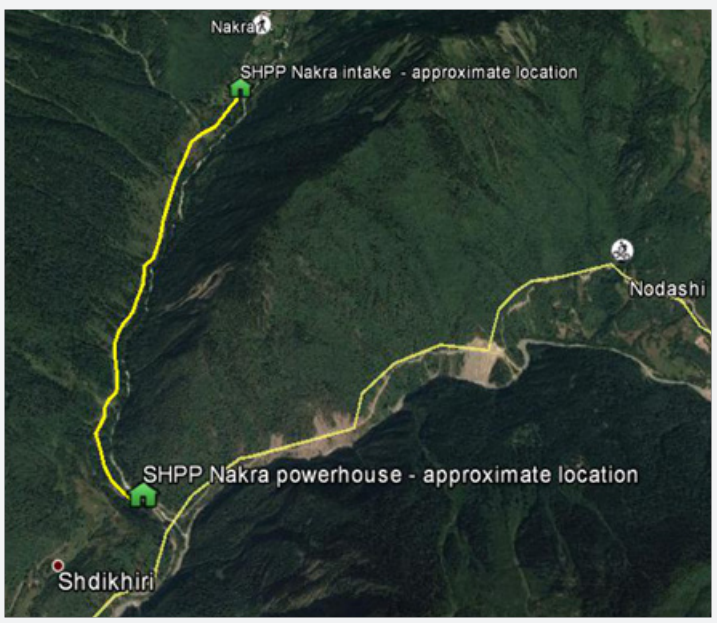

Figure 1: Project area of SHPP Nakra.

The project site of the SHPP Nakra is located near to the village of Nakra in north region of Georgia. According to the original design developed by Macedonian company Akvavat (Skopje, R. Macedonia) the small hydropower plant should be constructed on the Nakra River. During the execution of the construction works due to various reasons additional designs was needed to be developed. One of the reasons for new designs was the instability of the cut slopes of the existing unpaved road which leads to the village of Nakra and the intake of the hydro power plant. According to the original design the penstock should be constructed very close to the toe of the road cut slopes. One of the cut slopes was affected by landslide before works for construction of the penstock started. In order to provide conditions for construction of the penstock first task was to rehabilitate the landslide. Hence, one of the additional designs is related to the stabilization of this landslide (Figure 1).

The second issue which was raised during the construction works was related to the construction of separate waterproof barrier under the intake. According to the available geotechnical data the ground under the intake has relatively high hydraulic conductivity which can further lead to seepage beneath the intake and losses of significant quantities of water needed for proper functioning of the SHPP. In order to improve the ground conditions and to decrease the hydraulic conductivity of the ground it was decided to construct a waterproof barrier in front of the intake. Considering the available construction equipment, the access to the site and the local geology execution of grout curtain was most feasible design option.

Concept for Rehabilitation of the Landslide in the Vicinity of the Penstock Alignment

The concept for rehabilitation of the landslide in the beginning was based only on the site geology data, geodetic map of the landslide area developed before landslide occurred, photos of the landslide and the proposed penstock alignment 


\section{Civil Engineering Research Journal}

and penstock invert level. The site visit was held later before developing of the final design. The general idea was to stabilize the unstable section of the cut slope and to prevent safe ground conditions for excavation of the penstock trench and installation of the penstock. As per available data on ground topography it was detected that limited area of the considered cut slope is unstable but before site inspection the designers were not certain about the depth of the slip surface. Based on the borehole logs and geodetic data it seemed that it might be a deep-seated landslide. Anyway, in order to be on safe side, the preliminary design was developed assuming that the potential slip surface is deep-seated and the existing road which leads to Nakra village and the intake structure is affected (Figure 2\&3).

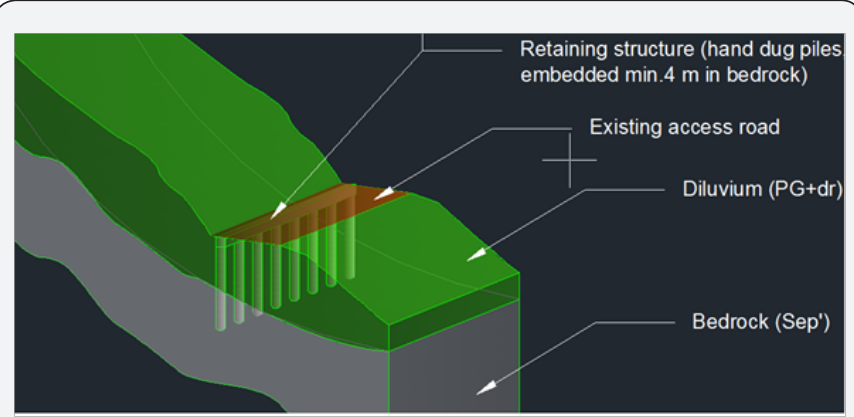

Figure 2: The preliminary design for landslide rehabilitation.

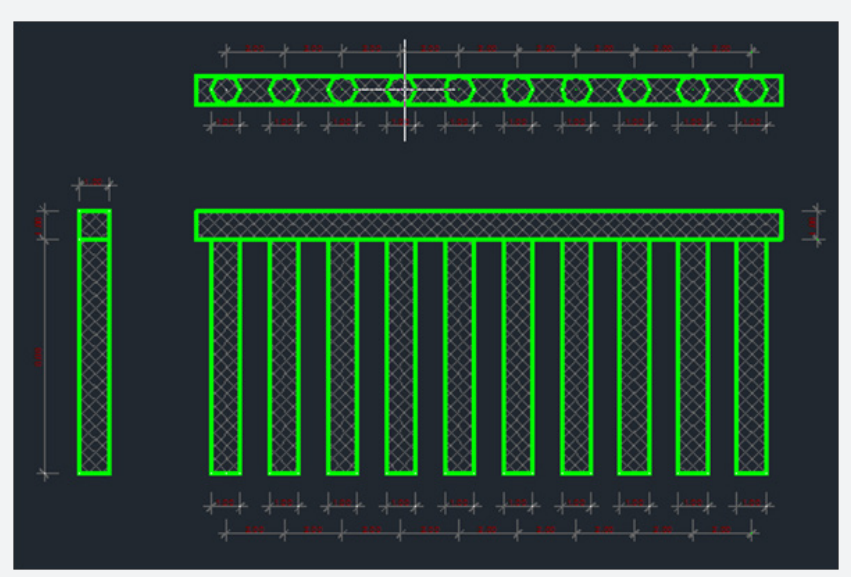

Figure 3: The proposed retaining structure (preliminary design).

The initial design concept involved construction of reinforced concrete pile wall fully embedded in the ground. The designed length of the piles was $8,0 \mathrm{~m}$ and the last section of the piles in length of $4,0 \mathrm{~m}$ was designed to be embedded in the sound bedrock. The diameter of piles was $1,0 \mathrm{~m}$ and the axial spacing of the piles was $2,0 \mathrm{~m}$. The piles are connected with reinforced concrete cap beam. The pile wall was segmented in separate sections divided by construction joints. In case of extension of the landslide area such approach helps to construct additional wall section without significant modifications of the design. The concept of the design was further developed in detail which is discussed in following chapters.
Preliminary Concept for execution of the Grouting works for Construction of Waterproof Screen

The preliminary concept for the execution of the waterproof barrier was consisted of several steps:

A. The waterproof barrier should be done as a separate structure without obstruction of the construction works on the intake and other structures;

B. The procedure for grouting was planned to be carried out in several steps:

a. Construction of reinforced-concrete raft as a platform for execution of the grouting;

b. Drilling of non-core grout boreholes;

c. Execution of the "in situ" permeability test in each borehole;

d. Grouting of all boreholes;

e. Performance of inclined (subvertical) core boreholes (core drilling with sampling) for checking the grouting quality. The boreholes are to be performed through the grouted portion of the ground;

f. Performance of "in situ" permeability test in each subvertical borehole to verify the permeability characteristics and functionality of the waterproof screen;

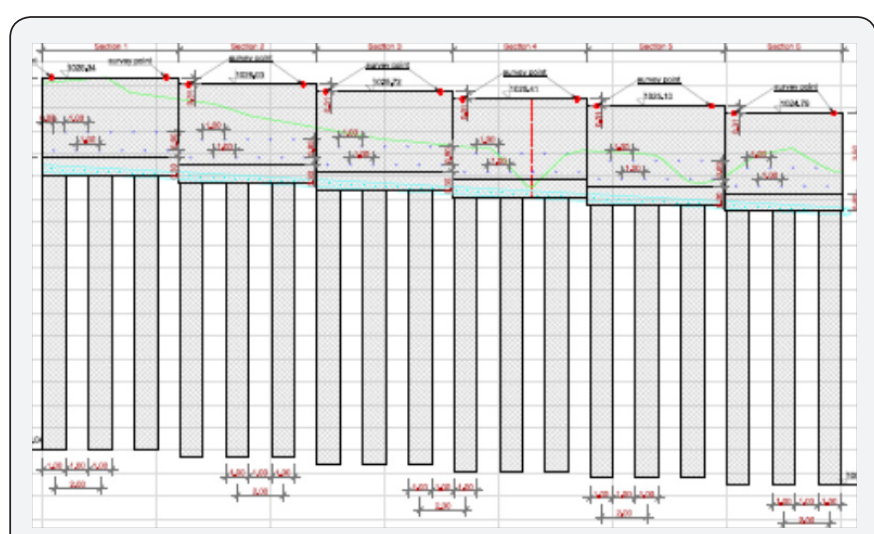

Figure 4: Longitudinal profile of the pile wall (final design).

The method of grouting is one of the major issues for the grouting works therefore special attention is paid to this matter. Also, the construction schedule was very tight so some of the structures had to be constructed in parallel. Before completion of the waterproof barrier design the works for construction of the intake were in progress. Therefore, it was very important to provide a proper access to the upstream side of the intake in order not to obstruct the construction works on the intake (Figure 4).

\section{The Final Design on Landslide Rehabilitation}

As mentioned before the concept for landslide rehabilitation was mostly based on geotechnical and geodetic data and photos 


\section{Civil Engineering Research Journal}

provided by the Client. Such data were sufficient for establishing a concept for landslide rehabilitation but not even remotely sufficient for developing of detailed design. Some of the data which were not available and are important for proper developing of detailed design are: detailed geotechnical investigations, mapping of the ground at the landslide area, location of the landslide boundaries and landslide elements such as primary and secondary cracks, head crack, toe crack, indications of slip surfaces etc. To be on safe side one of the essential design assumptions in this particular case was that the future landsliding will occur on a deep-seated slip surface. According to the available geotechnical report the geological boundary between the soil materials and the rock formations which are underlying the soil is located at the depth of approximately 5, $0 \mathrm{~m}$. Considering the governing ground and site conditions and the location of the penstock that will be built in the immediate vicinity of the landslide the worst case scenario was to consider that the future landsliding will occur at the contact between the soil and rock formations. The maximum level of the penstock invert in the area of the landslide is approximately $3,0 \mathrm{~m}$ below the road surface which is $2,0 \mathrm{~m}$ above the anticipated deepseated slip surface. This actually means that such landsliding will affect the penstock and it will have adverse effect on the operation of the hydro-power plant. Another design assumption related to the location of the slip surface was that the landsliding cannot occur through the rock formations, so the deepest area that can be affected by landsliding is the contact between soil and rock formations. In order to provide all necessary data for proper developing of the design first step was to conduct a site reconnaissance. The site reconnaissance was held in the end of November 2018 and based on the site reconnaissance findings following data were summarized:

A. The initial landsliding was shallow (no more than $2,5 \mathrm{~m}$ at the deepest point) and the area which was affected has irregular shape with size approximately 20,0x30m.

B. The landslide affected one portion of the road cut slope;

C. The shape of the existing slip surface is curved and irregular probably consisted of several smaller slip surfaces;

D. The ground is highly saturated;

E. Almost all of the cut slopes of the existing road are prone to instability, landsliding and rockfalls which means that special attention should be paid during the construction of the penstock;

F. The space for construction of the penstock and the pile wall is very limited, therefore from construction point of view the pile wall is more feasible to have one row of piles;

G. Extended geotechnical investigation works should be done; (Figure 5)

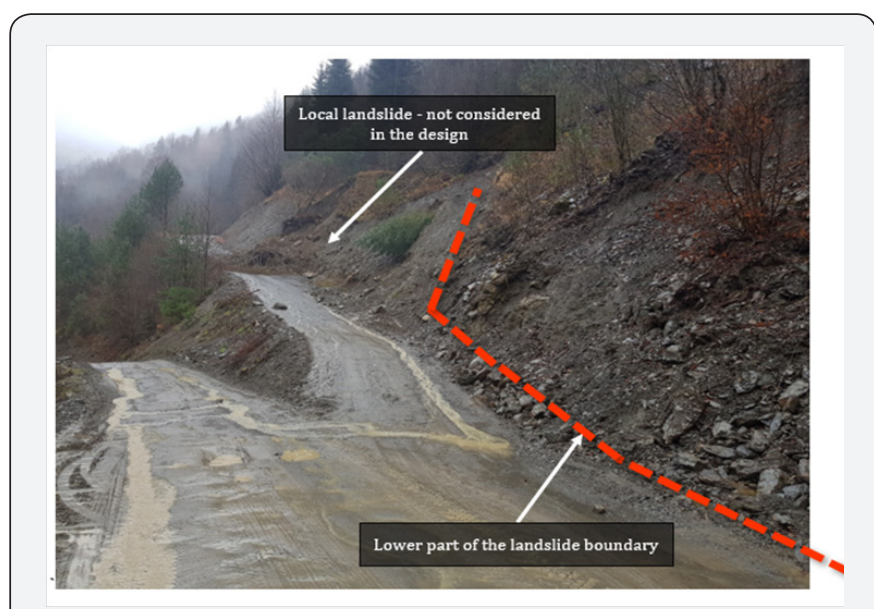

Figure 5: Cut slope of the existing road affected by the landslide.

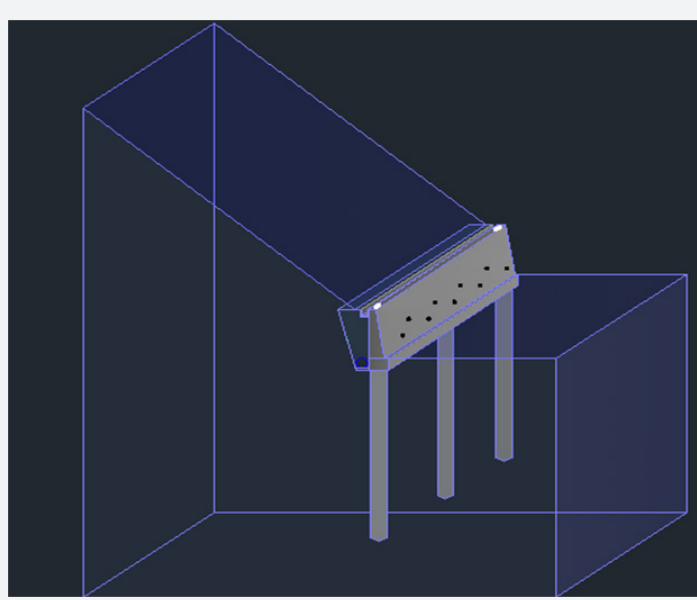

Figure 6: 3D model of one section of the retaining wall (final design).

Based on the findings from the site reconnaissance and the previously provided data the final design on landslide rehabilitation was developed. Unfortunately, at that moment there was no possibility to conduct extended geotechnical investigation works. The proposed rehabilitation measures involve construction of retaining pile wall in the toe of the cut slope affected with landsliding, drainage system of the retaining wall and surface water channel located behind the crest of the pile wall. The pile wall is divided in sections and each section is consisted of one row of reinforced concrete piles with diameter of $1000 \mathrm{~mm}$ and length of $\mathrm{L}=12,0 \mathrm{~m}$. The piles of each wall section are connected with reinforced concrete cap beam $(0,8 \times 1,2 \mathrm{~m})$. Above the cap beam a wall stem $(\mathrm{H}=3,5 \mathrm{~m})$ will be constructed in order to provide conditions for backfilling of the space between the cut slope and the wall stem. The backfilling will increase the local stability of the cut slope in the portion of the slopes close to the pile wall. The total length of the retaining structure is $\mathrm{L}=35,0 \mathrm{~m}$ and the length of each wall section is $\mathrm{L}=6,0 \mathrm{~m}$ with expectation of the last one which is shorter. The sections of the wall are separated by construction joints (Figure 6). 


\section{Civil Engineering Research Journal}

One of the findings during the site visit was that ground in the landslide area is very saturated, so in order to avoid building up of hydrostatic pressure which will act on the wall a drainage system is proposed to be constructed. The drainage system of the wall is consisted of drainage pipe embedded in the ground, drainage geocomposite installed behind the wall stem and two rows of weep holes which will be installed through the RC wall stem before concreting. The outlet (full pipe) of the drainage pipe will evacuate the captured drainage water out of the landslide area. The surface water channel is located behind the crest of the wall along the entire length of the wall. It will collect the surface water and will evacuate the water out of the landslide body.

\section{The analyses}

Different type of analyses was performed in order to provide proper design on the landslide rehabilitation measures. The designing phase started with back analyses which gave indications of the ground conditions which can lead to new landsliding. As mentioned before, the shallow slip surface occurred but the general idea was to assess the ground conditions which will trigger deep-seated slip surface. The results from the back analyses shows that if the cohesion of the soil drops from $c=22 \mathrm{kPa}$ to $\mathrm{c}=16 \mathrm{kPa}$ the factor of safety of the deep-seated slip surface located at the contact between soil and rock formations will be Fs=1 (neutral state of the slope equilibrium). This actually means that very small variation of the cohesion will be led to instability and will trigger deep-seated slip surface. The material properties of soil provided for neutral state of equilibrium of the anticipated slip surface (Fs=1) are later used to model the deepseated slip surface in the stability and stress-strain analyses. In these analyses the deep-seated slip surface is modeled as a thin soil layer with same shape and position as it was assessed in the back analyses. The material properties assigned to the slip surface layer are: $\varphi=240, c=16 \mathrm{kPa}$ and $\Upsilon=20 \mathrm{kN} / \mathrm{m} 3$. The values of angle of internal friction $(\varphi)$ and the unit weight $(\Upsilon)$ are provided from the geotechnical report. The value of the cohesion of the slip surface layer is back calculated. The back analyses are performed in Slide, a program for slope stability analyses which is based on limit equilibrium theory. Upon completion of the back analyses and providing the material properties of the anticipated deep-seated slip surface next step was completion of stress-strain analyses. The stress-strain analyses are carried out in Plaxis 2DAE program based on finite element method (FEM). The same ground model and material properties of the soil and rock used for back analyses are used for stress-strain analyses. The material properties used in the calculation model are tabulated in Table 1.

Table 1: Basic material properties used in the analyses.

\begin{tabular}{|c|c|c|c|c|}
\hline Material & Unit weight $\left[\mathbf{k N} / \mathbf{m}^{3}\right]$ & Cohesion $\left[\mathbf{k N} / \mathbf{m}^{2}\right]$ & Angle of Internal Friction & $\begin{array}{c}\text { Oedometric/Deformabili- } \\
\text { ty Modulus } \\
{[\mathbf{k P a}]}\end{array}$ \\
\hline Diluvium & 20 & 22 & 24 & 30000 \\
\hline Slip surface & 20 & 16 & 24 & 15000 \\
\hline Decomposed shales & 22 & 85 & 18.85 & 40000 \\
\hline Shales & 23 & 120 & 15 & 100000 \\
\hline
\end{tabular}

Table 2: Deformations and forces in the retaining structure.

\begin{tabular}{|c|c|c|c|c|c|c|c|c|}
\hline \multirow{4}{*}{$\begin{array}{l}\text { Structural } \\
\text { Element }\end{array}$} & \multirow{4}{*}{ LOAD CASE } & \multirow{2}{*}{\multicolumn{4}{|c|}{$\begin{array}{c}\text { Deformations [SLS] } \\
\text { Deformations in } \mathrm{X} \text { direction }\end{array}$}} & \multicolumn{3}{|c|}{ Forces in the structure [ULS] } \\
\hline & & & & & & \multirow{2}{*}{$\mathbf{M}$} & \multirow{2}{*}{$\mathbf{T}$} & \multirow{2}{*}{$\mathbf{A}$} \\
\hline & & & erpendicula & he struct & & & & \\
\hline & & $\operatorname{Min}(\mathrm{cm})$ & $\operatorname{Max}(\mathrm{cm})$ & $\Delta \mathrm{d}(\mathrm{cm})$ & $\begin{array}{c}\text { criteria } \\
\Delta \mathrm{d} \leq \mathrm{L} / \mathbf{1 0 0}\end{array}$ & [kNm'] & {$[\mathrm{kN}]$} & {$[\mathrm{kN}]$} \\
\hline \multirow{3}{*}{ Vertical Steam } & LC1 & $-0,70$ & $-1,40$ & 0,70 & $16,30 \mathrm{~cm}$ & 260,70 & 194,80 & $-225,00$ \\
\hline & LC2 & $-13,02$ & $-9,20$ & 3,82 & $16,30 \mathrm{~cm}$ & 287,80 & 217,70 & $-262,00$ \\
\hline & LC3 & $-18,00$ & $-12,96$ & 5,04 & $16,30 \mathrm{~cm}$ & 360,80 & 251,50 & $-275,70$ \\
\hline \multirow{3}{*}{ Piles } & LC1 & $-0,72$ & 0,11 & 0,83 & $16,30 \mathrm{~cm}$ & 698,60 & 196,90 & $-224,00$ \\
\hline & LC2 & $-9,20$ & $-3,60$ & 5,60 & $16,30 \mathrm{~cm}$ & 667,00 & 219,90 & $-257,00$ \\
\hline & LC3 & $-12,96$ & $-4,61$ & 8,36 & $16,30 \mathrm{~cm}$ & 953,60 & 254,80 & $-277,70$ \\
\hline
\end{tabular}

The stress-strain analyses are performed in several sequences starting with generation of initial stress-strain state which involves the site and ground conditions before commencement of the works for rehabilitation of the landslide. In this stage the material properties of the anticipated deep-seated slip surface are same as the material properties of the diluvium. The following sequences of the analysis involve construction of the pile wall and backfilling of the space between the pile wall and the cut slope. For the phase which involve construction of the structure the displacement of the structure is assessed as well as the bending moments, shear and axial forces in the structure. The stability analysis (c-phi reduction method) is done for each 
stage of the analysis. All described sequences of the analyses are performed for static and seismic loading. In the next step of the analyses the anticipated deep-seated slip surface is introduced in the model. As mentioned before in this stage reduced value for the cohesion is assigned to the slip surface layer. The analysis is then run for static and seismic loading and stability analysis is also performed for both load cases. Also, the bending moments, shear and axial forces generated in the pile wall are estimated in case of deep-seated landsliding. The established results of the stress-strain analyses are tabulated in Table 2.

\section{Monitoring of the retaining structure}

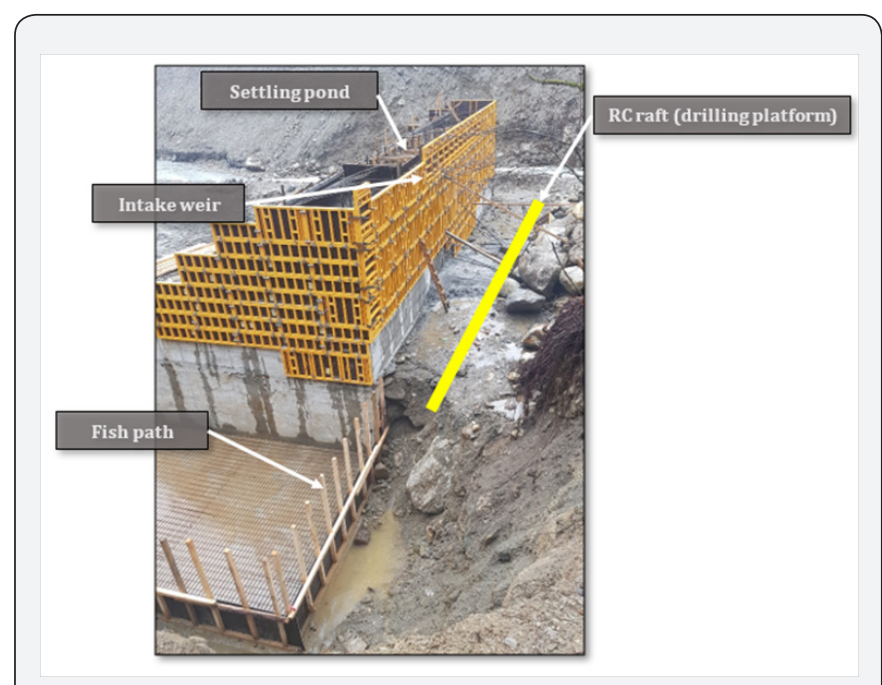

Figure 7: Position of the RC raft (drilling platform).

In order to provide data on the displacement of the retaining structure during the service life of the structure 12 survey points will be installed (two survey points on each wall section). The survey points will be installed upon construction of the retaining wall and the zero measurement will be done immediately after the survey points are installed. The location of the survey points is on the top of the wall stem at the beginning and at the end of each wall section. The monitoring of the structure will be carried out from two micro-trigonometric points which have to be located on stable ground. One of the considered options for monitoring of the displacement of the retaining structure was to install inclinometers through the piles. Namely, each wall section is separated from the adjacent section by construction joints. Hence, one inclinometer was planned to be installed for each section of the wall. This idea was abandoned due to various reasons but instead of installation of the inclinometers in the pile wall they will be installed in the ground in the vicinity of the structure (Figure 7).

\section{The final design on waterproof barrier}

According to the design for construction of the SHPP Nakra the intake structure is consisted of intake weir, fish path and settling pond. The weir of the intake structure is positioned in the middle of the intake and it is 25,0 m long (in perpendicular direction to the river flow). The fish path and the settling pond of the intake are positioned on both sides of the intake weir. At the very end, in addition to the fish path and the settling pond, wing walls are to be constructed. The geotechnical report prepared during the predesigning phase indicates that the site of the intake has unfavorable characteristics in respect to hydraulic conductivity and permeability of the ground. The possibility of water losses due to the high seepage rate through the ground (beneath the intake) may reduce the water quantities which will be collected by the intake and transferred to the settling pond and the penstock. Furthermore, the seepage of the river water beneath the intake can trigger suffusion which can generate excessive settlements of the intake and, over time, structural damages can occur. In order to deal with such adverse consequences, it is decided to go further in the detailing the design and to construct a waterproof barrier on the upstream side of intake. The waterproof barrier will be constructed in immediate vicinity of the intake. The waterproof barrier will be fully constructed in the ground (it will be fully embedded in the ground). Considering the site and ground conditions, the most feasible option for waterproof barrier is construction of grout curtain. In general, problems related to permeability of a soil or rock mass include:

a) Reduction in strength of foundation materials due to high seepage forces;

b) Loss of impounded water from a storage area;

c) High uplift forces at the base of water - retaining structures etc.

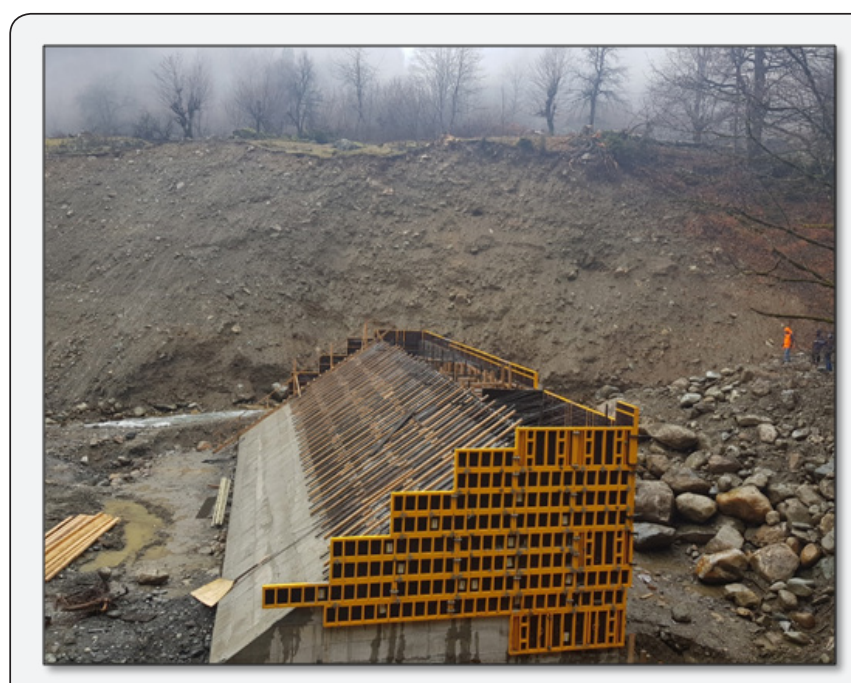

Figure 8: Intake during construction works.

The grouting is the process of placing an effective seal in a borehole. The sealing agents used are generally known as grouts. To be effective they must be easy to put in place and must have a very low permeability to limit the seepage of the water. In this particular case, upon construction of the grout curtain, the hydraulic conductivity should drop below $3 \mathrm{Lu}$. According to the 
available geotechnical data and the results obtained from the performed "in situ" permeability test, the hydraulic conductivity of the ground in the vicinity of the intake is approximately 1000 (one thousand) times higher than the required value. The objective of proper grouting is to replace the native material removed during drilling with grout that meets or exceeds the sealing capability of the removed native material (Figure 8). The grout curtain will be constructed in several construction steps:

i. Cleaning of the upstream area in front of the intake;

ii. Setting up of test field and performance of test grouting (ascending grouting method);

iii. Checking of the results of test grouting and adjustment of grouting method and grouting pressures on the basis of the established grouting test results. If the results of the test grouting are satisfactory then the grouting method and grouting pressures will remain as proposed in the design;

iv. Compaction and levelling of the foundation ground (area beneath the RC raft);

v. Construction of reinforced-concrete raft with size of $36 \mathrm{~m} \times 2,5 \mathrm{~m}$ and thickness of $0,3 \mathrm{~m}$;

vi. Core drilling of two investigation boreholes and performance of site permeability tests in both boreholes. Depending on the extracted cores it will be decided what type of permeability test will be done. If the extracted cores are mainly soil material Le Frank permeability test will be performed if the extracted cores are rock material Lugeon permeability test will be performed. The length of the investigation boreholes is $15 \mathrm{~m}$ and the permeability tests will be performed in $5 \mathrm{~m}$ long borehole test sections.

vii. Non-core drilling of grout holes with diameter of $56 \mathrm{~mm}$ or $76 \mathrm{~mm}$ to the final depth of $15 \mathrm{~m}$ ( 5 boreholes) and $12 \mathrm{~m}$ (13 boreholes). The grout holes will be first drilled to the $5 \mathrm{~m}$ depth then packer will be set on the top of grout section and grouting of the top $5 \mathrm{~m}$ of the hole will be done. The next step is drilling of the next grout hole up to $5 \mathrm{~m}$. After all grout holes are drilled and grouted to the depth of $5 \mathrm{~m}$ non-core drilling of the first grout hole will be done. This time the drilling of the top $5 \mathrm{~m}$ of the hole will be done through the grouted part of the hole and will proceed in natural ground to the depth of $10 \mathrm{~m}$. The next step is to put packer on $5 \mathrm{~m}$ depth and to grout the whole section between 5 and $10 \mathrm{~m}$ depth. When the grouting of this section is completed then packer will be placed on the top of the hole and the top $5 \mathrm{~m}$ of the hole will be grouted. The described drilling and grouting steps will be repeated for all grout holes. This is so call method of descending grouting and it will be applied to all grout holes.

viii. Performing of two subhorizontal core boreholes through the grout curtain; ix. Performing of Lugeon site permeability tests in the core boreholes;

x. Additional grouting in new boreholes (this is optional step depending on the results of the site permeability test. If the permeability of the ground is less than $3 \mathrm{Lu}$ then additional grouting will not be carried out);

In order to have proper conditions for positioning of the drilling rig and execution of the grouting works, a reinforcedconcrete (RC) raft will be constructed. The RC raft will be constructed in front of the intake as indicated in the drawings. The proposed size of the $\mathrm{RC}$ raft is $36,0 \times 2,5 \mathrm{~m}$ and the thickness of the RC raft is $0,3 \mathrm{~m}$. According to the design it will be reinforced using ribbed steel reinforcement bars. Before installation of the formwork and rebars, the foundation soil will be properly compacted and levelled. After proper compaction and levelling of the foundation soil the formwork will be installed, and a $10 \mathrm{~cm}$ thick layer of lean concrete will be placed. The drilling of the grout holes will be performed through the RC raft. Upon construction of the RC raft the geotechnical and grouting works will start.

\section{Test field}

In order to prove the proposed grouting works and the grouting method a test grouting on separate test field will be fist done. The location of the test field is close to the location of the future grout curtain in order to have similar ground conditions. If the test grouting is successful, then the grouting works on the grout curtain may start. The test grouting is planned to be performed in 3 grout holes located on 2,0 spacing between them. The test grout holes will be performed to the depth of $15 \mathrm{~m}$. The test grouting will be carried out in same manner as the grouting of the grout curtain only this time ascending grout method instead of descending method will be used. This means that the boreholes will be drilled to the final depth of $15 \mathrm{~m}$ then the grouting will be performed. If the test grouting shows that the proposed grouting method is not proper for current ground conditions, then modification of the design should be done.

\section{Program for geotechnical works and grouting}

Regardless of the number of investigation boreholes or other preconstruction activities, information on the size and continuity of groutable natural openings in rock below the surface will be relatively meager at the start of grouting operations and only slightly better after the grouting is completed. The presence of groutable voids can be ascertained before grouting and verified by grouting, but their size, shapes and ramifications will be largely conjectural. In large measure, the "art" of grouting consists of being able to satisfactorily treat these relatively unknown subsurface conditions without direct observation. There are different grouting procedures, but in this particular case curtain grouting will be used. Curtain grouting is the construction of curtain of barrier of grout by drilling and 
grouting a linear sequence of holes. Its purpose is to reduce permeability. The curtain may have any shape or attitude. A grout curtain may be made up of a single row of holes of it may be composed of two or more parallel rows.

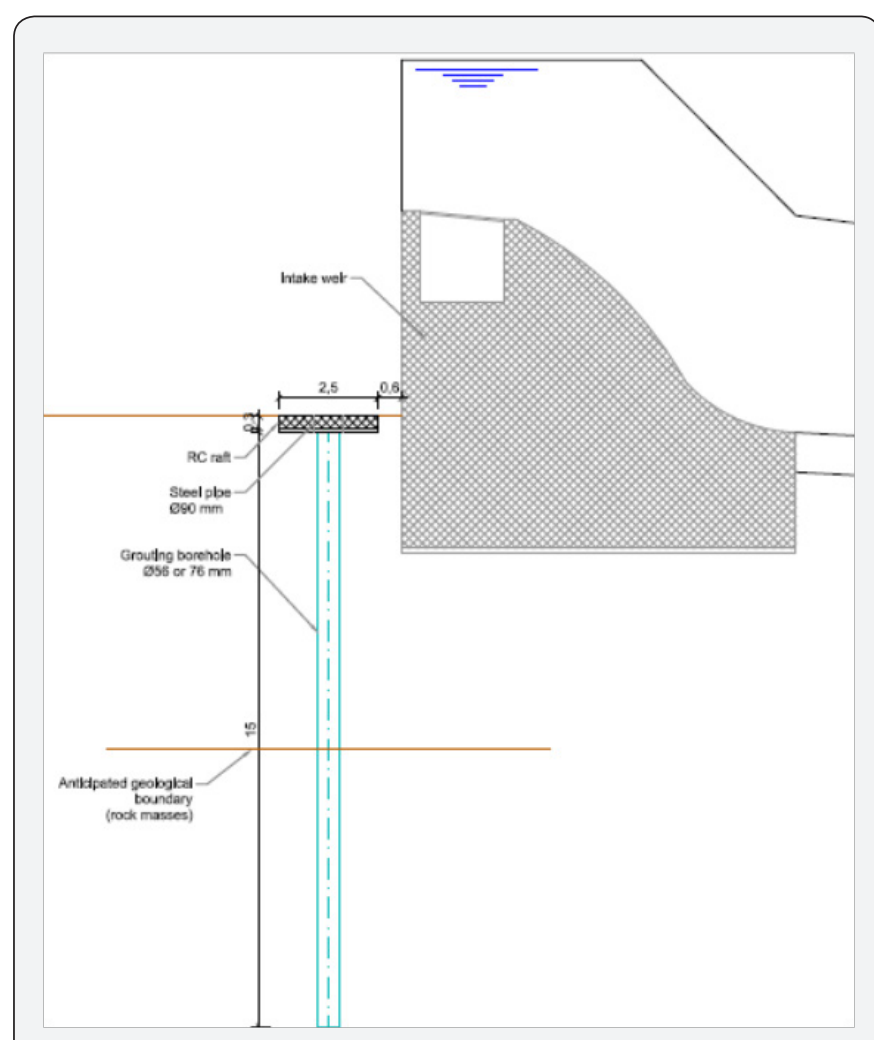

Figure 9: Position of RC raft and grout curtain (upstream side of the intake).

Based on the results from the investigation drilling of boreholes NK-WI 103 and NK-WI-104 located on the right bank of Nakra River, as well as on the results provided from Le Frank site permeability test, it can be concluded that in the area of the intake, certain interventions are needed in terms of improvement of the permeability characteristics of the encountered soil and rock materials to a certain depth. By analyzing the core extracted from the investigation boreholes (available borehole logs) and geological profiles it can be concluded that from the ground surface up to depth of 4,0-8,0m, quaternary alluvial-proluvial /moraine sediments are encountered. These sediments are consisted of clayey sands with low content of clay and gravels with rock boulders which originate from the bedrock. In the depth, the underlying layers are consisted of cracked and decomposed rock masses. Based on the site permeability tests (performed at depth of $0,0-6,0 \mathrm{~m}$ ) it can be concluded that the rock masses have good hydraulic conductivity i.e. there is a seepage of the ground water through the rock masses in the area of the intake (Figure 9).

Considering the above-mentioned and to reduce the hydraulic conductivity of the rock masses as well as to improve the bond between the intake structure and the natural ground, additional geotechnical works i.e. investigation drilling and grouting works are proposed:

a. Performance of two additional investigation boreholes (in the river bed approximately 3,0-5,0m upstream from the intake) to the depth of $15,0 \mathrm{~m}$;

b. Performance of Le Frank and Lugeon "in situ" permeability tests depending on the site geology. In total 6 site permeability tests.

c. The execution of the grout curtain will have impact on following:

d. reduction of the ground water seepage through the rock masses in the immediate vicinity of the intake (beneath the intake),

e. integration of the rock masses,

f. improvement of the resistance on weathering and erosion

All this action is needed in order to reduce the seepage of the ground water (produced by the flow of the Nakra River) beneath the intake and extension of the service life of the structure. Considering the results from the existing engineering-geological and hydrogeological investigations, the ground morphology as well as the expected results from abovementioned additional investigation works, the length of the grout curtain would be approximately $36,0 \mathrm{~m}$. The depth of the grout curtain will depend on the results from investigation works (to the depth of $15,0 \mathrm{~m}$ ) or will be determined as per criterion of minimum allowable hydraulic conductivity of the rock masses $\mathrm{K} \leq 3 \mathrm{Lu}$. This criterion is adopted having in mind the spacing of the grout holes (grout curtain with one row of holes) and the average thickness of the grout curtain of 1,0-2,0m [1-3].

\section{Conclusion}

The project area chosen for construction of SHPP Nakra is very difficult from construction point of view. The ground topography and the site geology are very unfavorable for execution of earth works and make the implementation of this project very challenging task. Speaking about the designs on landslide rehabilitation and grout curtain the designers faced a lot of difficulties and uncertainties during the designing phase. Some of the most significant issues were:

A. The geotechnical investigation works performed on the site are not intended for rehabilitation of the landslide and proper dimensioning of grouting works. The location of the boreholes and the scope of laboratory testing's are not at satisfactory level so the provided data on material properties of soil/rock materials were very limited. There are no investigation boreholes in the landslide body and also there is no a geophysical survey on the landslide; 
B. The construction works on the intake started before developing of the designs on landslide rehabilitation and grout curtain, so the time frame for completion of the designs was very limited;

C. The existing road at the landslide area is approximately $6 \mathrm{~m}$ wide and during the works for rehabilitation of the landslide it must be operational. This actually means that the space for the construction activities is very limited and proper drilling rig for execution of the piles is very difficult to use in this case. Therefore, manual excavation of the pile shafts is probably more feasible option;

D. The area in front of the intake is limited and the access to the upstream side of the intake is very narrow;

Our response as a designer in such situation was introducing design assumptions which will enable us to work on safe side and will protect the interest of the Client but in same time the designs will be a little bit more expensive due to the reasons listed above. So, following actions and design assumptions were considered for the landslide design:

a. The actual slip surface of the occurred landslide is shallow but there is possibility for further instability which can involve deep- seated slip surfaces located at the contact between the soil material and the bedrock. The retaining structure is analyzed to prevent deep-seated land-sliding;

b. Back analyses were performed to assess the conditions that can lead to land-sliding involving deep-seated slip surfaces;

c. The analyses were performed using different analyses method and two different design codes;

d. Monitoring of the pile wall will be carried out in the post construction phase;
Regarding the design on grout curtain following is done:

i. In the design is stated that it is highly recommended to do test grouting before construction of the grout curtain;

ii. Before start of the grouting works two additional core boreholes will be drilled and in each borehole permeability tests will be performed then the grouting method will be verified;

iii. Upon completion of the grouting works two subvertical core boreholes will be done and, in each borehole, Lugeon permeability test will be done;

iv. Regardless the fact that the both designs are based on rigid design assumptions due to lack of input data the experience on similar projects teaches us that adjustment of the designs during the execution of the works is almost inevitable. Therefore, collaboration between the Contractor, Client and the Designer as well as designer supervision during the execution of the works is very important. This case one more time proves that execution of the geotechnical designs is more or less related to regular presence of the designer on the site which will give him opportunity to adjust the design on the current ground and site conditions.

\section{References}

1. GeoTechServices (2016) Geotechnical report on engineeringgeological investigation for construction sites of "Nakra" HPP and penstock construction.

2. Maneswara Rao NSV (2011) Foundation design theory and practice. John Wiley \& Sons (Asia) Pte Ltd, Solaris South Tower, Singapore.

3. Smoltczyk U (2003) Geotechnical handbook procedures.

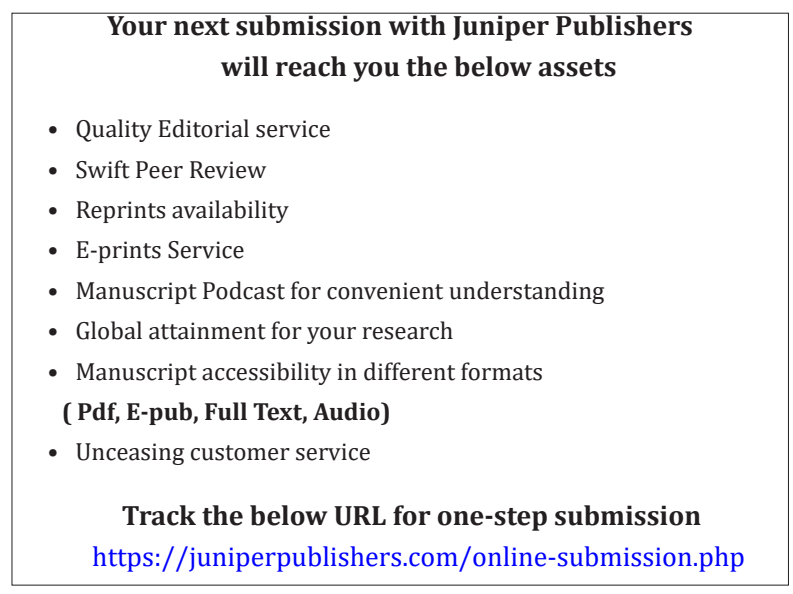

